\title{
Impact and sustainability of low-head drip irrigation kits, in the semi-arid Gwanda and Beitbridge Districts, Mzingwane Catchment, Limpopo Basin, Zimbabwe
}

\author{
Richard Moyo ${ }^{\mathrm{a}, *}$, David Love ${ }^{\mathrm{b}, \mathrm{c}}$, Marloes Mul ${ }^{\mathrm{a}, \mathrm{d}}$, Walter Mupangwa ${ }^{\mathrm{c}}$, Steve Twomlow ${ }^{\mathrm{c}}$ \\ ${ }^{a}$ Department of Civil Engineering, University of Zimbabwe, P.O. Box MP167, Mount Pleasant, Harare, Zimbabwe \\ ${ }^{\mathrm{b}}$ WaterNet, P.O. Box MP600, Mount Pleasant, Harare, Zimbabwe \\ ${ }^{\mathrm{c}}$ ICRISAT Bulawayo, Matopos Research Station, P.O. Box 776 Bulawayo, Zimbabwe \\ ${ }^{\mathrm{d}}$ UNESCO-IHE Institute for Water Education, Westvest 7, P.O. Box 3015, 2601 DA, Delft, The Netherlands
}

\begin{abstract}
Resource-poor smallholder farmers in the semi-arid Gwanda and Beitbridge districts face food insecurity on an annual basis due to a combination of poor and erratic rainfall (average $500 \mathrm{~mm} / \mathrm{a}$ and $345 \mathrm{~mm} / \mathrm{a}$, respectively, for the period 1970-2003) and technologies inappropriate to their resource status. This impacts on both household livelihoods and food security. In an attempt to improve food security in the catchment a number of drip kit distribution programmes have been initiated since 2003 as part of an on-going global initiative aimed at 2 million poor households per year. A number of recent studies have assessed the technical performance of the drip kits in-lab and in-field.

In early 2005 a study was undertaken to assess the impacts and sustainability of the drip kit programme. Representatives of the NGOs, local government, traditional leadership and agricultural extension officers were interviewed. Focus group discussions with beneficiaries and other villagers were held at village level. A survey of 114 households was then conducted in two districts, using a questionnaire developed from the output of the interviews and focus group discussions.

The results from the study showed that the NGOs did not specifically target the distribution of the drip kits to poor members of the community (defined for the purpose of the study as those not owning cattle). Poor households made up 54\% of the beneficiaries. This poor targeting of vulnerable households could have been a result of conditions set by some implementing NGOs that beneficiaries must have an assured water source. On the other hand, only $2 \%$ of the beneficiaries had used the kit to produce the expected 5 harvests over the 2 years, owing to problems related to water shortage, access to water and also pests and diseases. About 51\% of the respondents had produced at least 3 harvests and $86 \%$ produced at least 2 harvests. Due to water shortages during the dry season $61 \%$ of production with the drip kit occurred during the wet season. This suggests that most households use the drip kits as supplementary irrigation. Conflicts between beneficiaries and water point committees or other water users developed in some areas especially during the dry season.

The main finding from this study was that low cost drip kit programs can only be a sustainable intervention if implemented as an integral part of a long-term development program, not short-term relief programs and the programme should involve a broad range of stakeholders. A first step in any such program, especially in water scarce areas such as Gwanda and Beitbridge, is a detailed analysis of the existing water resources to assess availability and potential conflicts, prior to distribution of drip kits.
\end{abstract}

(C) 2006 Elsevier Ltd. All rights reserved.

Keywords: Access to water; Drip kits; Intervention targeting; Sustainable intervention; Water availability

\footnotetext{
* Corresponding author. Present address: Department of Land and Water Resources Management, Midlands State University, P. Bag 9055, Gweru, Zimbabwe. Tel.: +26311 719515; fax: +26354 26233 .

E-mail addresses: moyor@msu.ac.zw, richmoyo2004@yahoo.co.uk (R. Moyo), davidlove@science.uz.ac.zw, d.love@cgiar.org (D. Love), mul@ eng.uz.ac.zw, m.mul@unesco-ihe.org (M. Mul),w.mupangwa@cgiar.org (W. Mupangwa), s.twomlow@cgiar.org (S. Twomlow).
} 


\section{Introduction}

Small-scale farmers are the largest population group in the agriculture sector of most developing countries and are now perceived as key players in increasing global food production and achieving food security (Frausto, 2000). In the past, it was thought that large-scale irrigation schemes could help overcome production shortfalls in these regions. Unfortunately, few of the large-scale schemes have met the ambitious targets identified at their conception (e.g. Samakande et al., 2004; Senzanje et al., 2003). The cost of continued maintenance are often not met, and a large number of schemes throughout Zimbabwe, and for that matter much of sub-Saharan Africa, have been identified by the Ministry of Water Resources and Infrastructure Development as requiring rehabilitation to allow for better utilization of existing irrigation potential (Mutezo, 2005). Furthermore, many dams developed for irrigation purposes are heavily under-utilized (Love et al., 2005; Mutezo, 2005).

A global initiative on drip kit distribution has been developed for smallholder irrigation by the USAID Linkages for the Economic Advancement of the Disadvantaged (LEAD) project. This initiative is expected to benefit 30 million poor households around the globe ( 2 million per year) by 2015 and should bring 1 million hectares under irrigated cultivation over the next 15 years (Hussain et al., 2002). The focus on upgrading smallholder agriculture is essential, since smallholder farmers make up around half of the food insecure population of the World (FAO, 2004).

The low-head drip kit can irrigate around $100 \mathrm{~m}^{2}$ as shown in Fig. 1. The capacity of the drum (tank) is normally 100-200 1, and it must be filled once or twice a day. The drum must be placed at a height of 1-2 $\mathrm{m}$ above ground, to provide the required pressure. Water then flows from the drum into $10-30 \mathrm{~m}$ long drip-lines, in which emitters are regularly spaced to release water (Chigerwe et al., 2004).

A number of studies have been undertaken in Asia (e.g. Behr and Naik, 1999; Westarp et al., 2004) to assess the requirements for effective distribution and sustainable and efficient utilization of drip kits. The enabling conditions include availability of spares, technical and agronomic support, and continuing availability of a minimum water requirement. Access to and adequacy of good water quality surface and ground water was also deemed important for sustainable use of the kits. It also recommended that the water source for the drip kit should be within 15-30 m of the garden. These conditions are important in light of the fact that kits are supposed to be used through out the year. For efficient utilization, recipient households are supposed to grow up to three cycles of crops per year, including at least one cycle of vegetable crops, for Zimbabwe this is in the winter dry season and early maize or bean crop at the start of the wet season, which can be harvested in December.

Since 2003 the LEAD program in Zimbabwe has distributed over 20,000 low-head drip irrigation kits to food-insecure families for developing household nutrition gardens. More than 1000 such kits have been distributed to rural households in Gwanda and Beitbridge Districts. This has the potential to impact both on household livelihoods and on national food security. The LEAD program worked with more than six Non-Government Organizations (NGOs) in the distribution of the drip kits in the two districts. Each NGO developed its own targeting criteria for beneficiaries in their respective communities and their own training/support programs.

Several lab and on-farm studies have been carried out in Zimbabwe on the technical evaluations of the drip kit performance including how it affects crop yield and water productivity (Chigerwe et al., 2004; Maisiri et al., 2005; Nkala, 2003; Senzanje, 1997, 1998; Senzanje et al., 2003, 2004). From these studies it was found that low cost drip systems had a potential to be beneficially adopted by smallholder farmers.

To complement the existing work on the technical performance of drip kits, this study was carried out to assess the impacts and sustainability of the drip kit program implemented by a range of NGOs in the Mzingwane Catchment, Zimbabwe, in relation to water availability, access to water, utilization of the kits and the targeting of beneficiaries. The

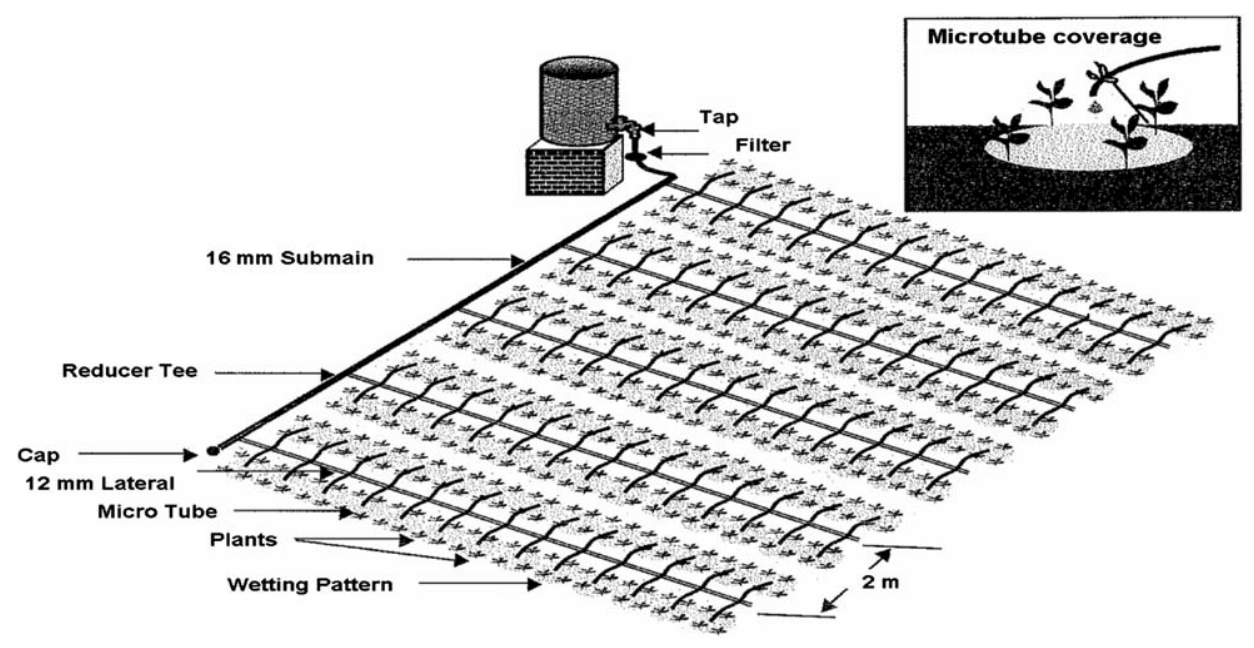

Fig. 1. Schematic diagram of a drip kit (Keller, 2004). 
study also explored the conflicts arising due to the use of water from existing water sources for drip kits.

\section{Materials and methods}

\subsection{Study area}

The study area is a semi-arid area of southern Zimbabwe, with a mean annual rainfall of between $500 \mathrm{~mm} / \mathrm{a}$ at West Nicholson near Gwanda in the northern area, to $345 \mathrm{~mm} / \mathrm{a}$ at Beitbridge in the southern area (derived from rainfall records from 1970 to 2003). These households face food insecurity on an annual basis due to a combination of erratic rainfall (ranging from 180 to $850 \mathrm{~mm} / \mathrm{a}$ based on data from 1970 to 2003) and technologies inappropriate to their resource status. The soils are generally infertile, sandy soils, derived from Archaean granites and gneisses of the Zimbabwe Craton and Limpopo Belt (Ashton et al., 2001). The soils are well to very well drained, moderately shallow, greyish brown to yellowish red gravely coarse-grained sands to sandy loams, with an acidic soil moisture. These soils are considered to be unsuitable according to conventional criteria for commercial irrigation, but are considered adequate for traditional forms of small-scale farming, water availability being the major constraint (Anderson et al., 1993). Sources of water for both domestic and irrigation include groundwater and tributaries of Lower Thuli and Mzingwane rivers.

Portions of two districts in Matabeleland South Province namely Gwanda and Beitbridge, were selected for this study (see Fig. 2). In selecting the wards to carry to the study consideration was given to areas where NGOs were most active in the distribution of drip kits. In Gwanda the study was done in Wards 14, 17 and 18 while in Beitbridge the study was done in Wards 4, 5, 6 and 7. These wards had received the highest number of drip kits distributed by the NGOs namely Intermediate Technology Development Group (ITDG), Hlekweni, Lutheran Development Services (LDS), Dabane, Compassion Ministries, Mvuramanzi and World Vision. The selected wards were also in the drier parts of the districts, where the impact of such technology would be expected to be higher.

The districts of Gwanda and Beitbridge have a combined population of over 220,000 and had an average growth rate of $5.6 \%$ in 2002 . There are close to 50,000 households in the two districts with an average household size of 4.4 people (Government of Zimbabwe, 2003). Most of this population lives in densely populated communal lands which are smallholder-farming lands, held under semi-traditional tenure. Communal areas of Gwanda and Beitbridge are mostly grazing areas with over $70 \%$ of land being heavily grazed (Anderson et al., 1993). Crops grown under rain fed agriculture frequently fail. An unpublished survey from the area suggests that households seem to rely on livestock and access to irrigation (if any), along with external sources (remittances from family members in urban areas, food aid, etc.) for their income (Sithole, personal communication, 2006). In this context, the impact of drip kit distribution could be very significant in improving livelihoods.

\subsection{Focus group discussions}

Focus group discussions were organised in three villages (Sengezane, Mnyabeze-D and Majiya) in different wards in

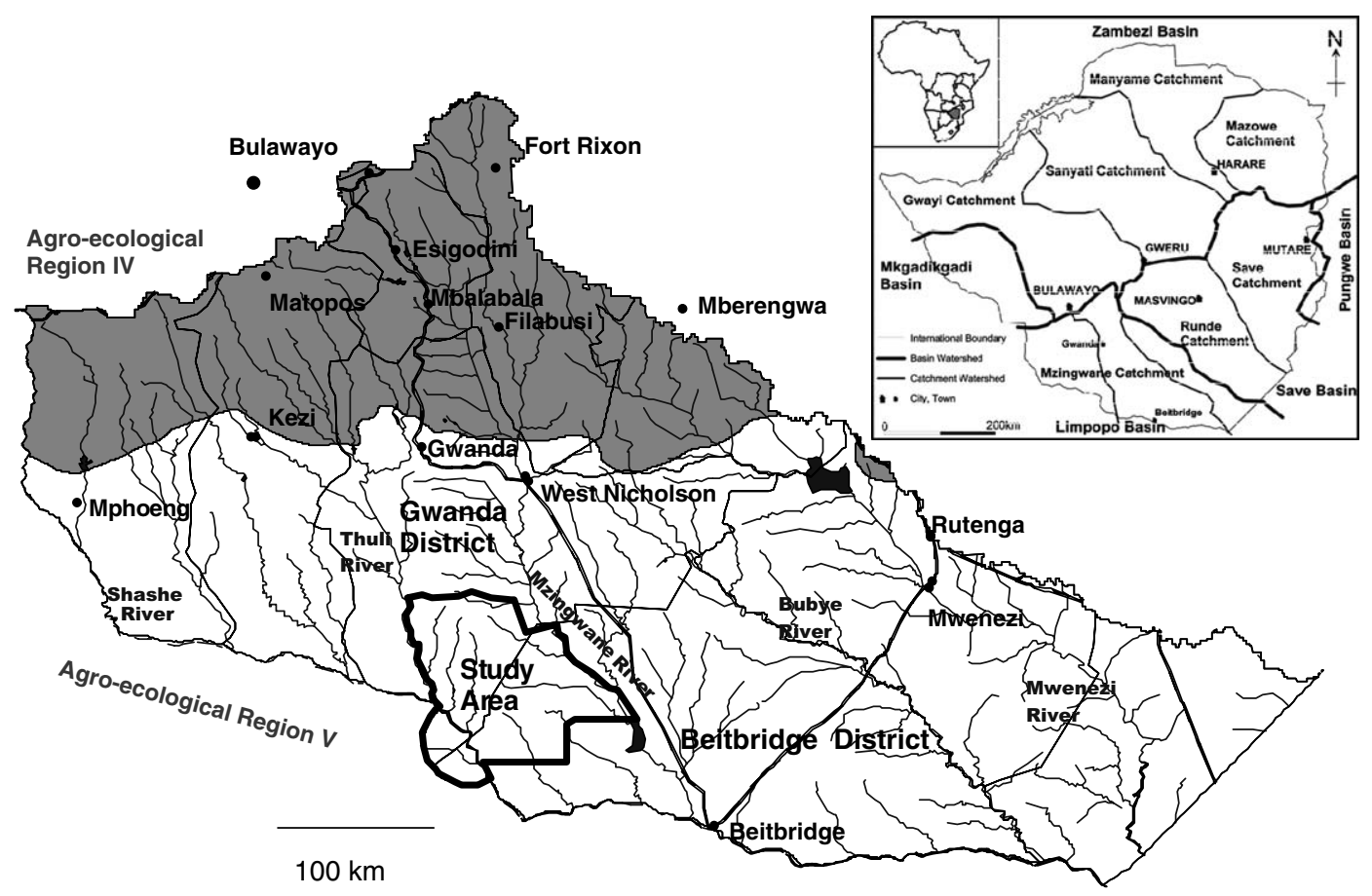

Fig. 2. Location of the study area in Mzingwane Catchment. Inset: Location within Zimbabwe. 
the study area. These villages were selected after discussions with the implanting NGOs and the local authority. An effort was made to have at least 10 participants take part in each of the focus group discussions. The objective of these focus group discussions was to collect in-depth qualitative information about groups' perceptions, attitudes and their experiences on the use of drip kits. In an open exchange of ideas, participants were asked of their successes and failures in relation to the kits, their fears, constraints and their ideas on how the programme could be improved and how it should be implemented in future. Participants were also asked if they had been able to use the kit throughout any given year and if indeed the adoption of the drip kit had improved their livelihoods.

\subsection{Field survey}

A quantitative field survey was undertaken using questionnaire developed from the results of the focus group in villages in the six wards of Gwanda and Beitbridge where there had been strong NGO drip kit distribution activities. A total of 114 households out of the 1151 households who had received drip kits in 12 villages in the two districts were interviewed $(\approx 10 \%)$. An effort was made to avoid those villages where the focus group discussions had been carried out to avoid interviewing those with pre-conceived answers to the questionnaire. Lists of names of beneficiaries were collected from respective implementing NGOs and where possible the names of contact farmers who helped in locating the beneficiaries to be interviewed on the ground.

The beneficiaries were asked which kit they received, if they had installed and used the kit, where it was installed, the crops they grew, problems related to the gardens, water sources, their knowledge on the operation and maintenance of the kit, their perceptions on the kit and their advice to the implementing agents to improve future kit distribution programs. The beneficiaries were interviewed at the garden site where the kit had been installed or was supposed to be installed. This allowed direct observations of the installed drip kits and verification of the interviewee response. Beneficiaries were also requested to demonstrate the operation and maintenance of the drip kit.

The quantitative survey data was analysed using the statistical package SPSS. Data was initially entered and coded using Microsoft Excel, which was then used for correlation analysis between different factors relating to the use of the kit and graphical summaries of the results.

\section{Results and discussion}

\subsection{Focus groups discussions}

Almost all participants in the focus group discussions stated that they were motivated to try the drip kits because it was a new technology that they had not previously used. They stated that drip kits were ideal for their environment as it was water saving and that there were nutritional and economic benefits. However, this viewpoint is likely to have been influenced by the fact that the implementing NGOs state these two points as the main advantages of distributing drip kits, when they are encouraging households to participate in the drip kit distribution programme.

From the discussions in Sengezane and Mnyabeze-D it was clear that the beneficiaries were not able to fully utilize the drip kits they had received, apparently due to water shortages. Most of the beneficiaries in these villages were dependent on community boreholes for their water. The low priority status of the drip kits in water allocation from the community boreholes came out in the discussions, which resulted in some beneficiaries being denied access to water during the dry season. The beneficiaries were also concerned on the long distances that they had to travel to fetch water and they felt this competed for labor with other household activities. In some discussions, participants suggested that the implementing agencies should first drill boreholes that would have been used by the drip kit users.

In the third village (Mnyabeze-D), most beneficiaries had their own water sources and the main concern raised was clogging of the drip kits as the water was said to be saline. Some beneficiaries also claimed that they had problems accessing or affording some of the inputs such as seed, fertilizer and pesticides.

The initial technical training received from the implementing agencies on the use of the drip kits was adequate for most of the beneficiaries' needs; although participants argued for more sustained training on crop production techniques for high value crops such tomatoes, peas, onion and butternut. Many participants stated that they also needed to be advised on the cropping calendar and on pest control.

The overall conclusion from the focus group discussions was that the drip kits had not met the expectations raised by the NGOs when the drip kits were introduced, since fewer crops per year were being produced than the NGOs had said was the objective. The reasons cited were water shortages, lack of markets for their produce, technical problems and lack of follow up visits by the implementing agencies. Beneficiaries also felt that they needed to be consulted prior to such programmes being implemented.

\subsection{Survey results: targeting by $N G O s$}

The 114 households who were identified from the lists of NGOs as recipients were interviewed but the analysis of the data was done on the basis of the 112 households who had actually used the kit.

According to NGO representatives, NGOs targeted beneficiaries based on poverty levels, with ownership of cattle was treated as an indicator of socio-economic status (Moyo, 2005). The exception was ITDG, which used an ability based criteria: a potential beneficiary had to show evidence of well-fenced garden and water source not more than $300 \mathrm{~m}$ from the garden. World Vision and Compassion in Beitbridge also required that the proposed gardens 


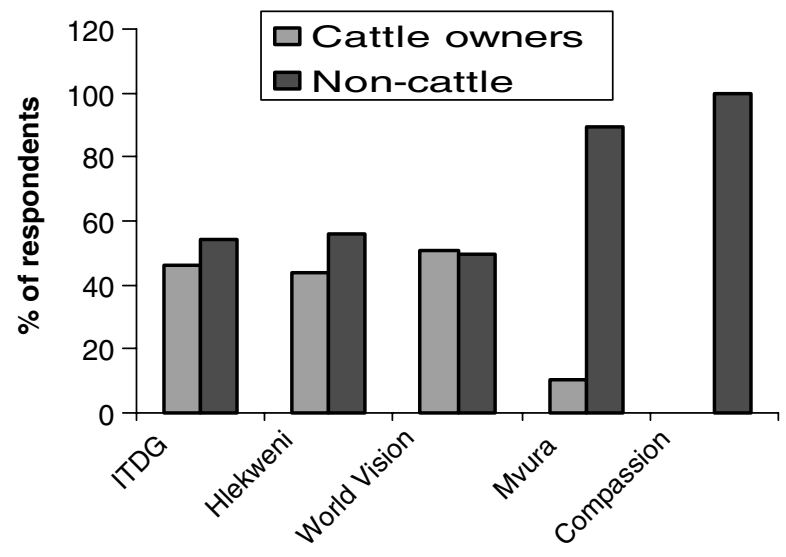

Fig. 3. Cattle-owning status of households receiving drip kits from 5 different NGOs.

be near to the water sources. Evidence from the formal survey shows that households receiving the drip kits could be divided into two basic socio-economic classes with one class consisting of those who owned cattle being the wellto-do farmers, and a second class comprising those who owned no cattle being the poor farmers (see Fig. 3). Of the 114 respondents, $46 \%$ owned cattle and the rest did not. It can be seen that Hlekweni and World Vision failed to meet their targeting criteria, as just over half of those who benefited were poor households. Mvuramanzi and Compassion did meet their target with over $90 \%$ of the farmers coming from poorer households.

\subsection{Survey results: water sources}

Survey results from the 114 households indicated that $73 \%$ of beneficiaries were dependent for irrigation water on existing groundwater sources i.e. boreholes and deep and shallow wells. Among those beneficiaries with at least one water source, $52 \%$ of them travelled more than $100 \mathrm{~m}$ as shown in Table 1.

A substantial number, $25 \%$ travel more than $1 \mathrm{~km}$ to fetch water for their drip kit nutritional gardens. The targeting by NGOs had an influence on this. For example, $63 \%$ of ITDG beneficiaries, which used an ability-based criteria for targeting, had water sources within $100 \mathrm{~m}$ of their gardens and only $5 \%$ had water sources more than $1 \mathrm{~km}$ from their garden site. This was in contrast to Hlekweni, for whom only $23 \%$ of their beneficiary's gardens were located within $100 \mathrm{~m}$ of water source, $54 \%$ of beneficiaries travelling more than $1 \mathrm{~km}$ to collect their water. However, there was a significant difference $(p<0.05$, chi-squared test) between the two socio-economic groups of farmers. Cattle owners tended to travel longer distances than the non-cattle owners, which could be attributed to them owning some means of transporting water in bulk. A comparison between the two districts revealed that beneficiaries in Beitbridge were travelling shorter distances when compared to those in Gwanda. Sixty nine percentage of the beneficiaries in Beitbridge fetched water from water sources that were less than
Table 1

Distances of water sources from nutritional gardens in Gwanda and Beitbridge $(n=112)$

\begin{tabular}{lcc}
\hline Distance $(\mathrm{m})$ & Percent & Cumulative percent \\
\hline$<100$ & 48 & 48 \\
$100-500$ & 20 & 68 \\
$500-1000$ & 7 & 75 \\
$>1000$ & 25 & 100 \\
Total & 100.0 & \\
\hline
\end{tabular}

$100 \mathrm{~m}$ from their gardens compared to $38 \%$ for the beneficiaries in Gwanda. There were no beneficiaries who fetched water from distances of greater than $500 \mathrm{~m}$ in Beitbridge compared to $50 \%$ who fetched water from this same distance in Gwanda. This could be attributed to the targeting condition of World Vision and Compassion in Beitbridge of having the gardens next to the water sources.

A majority $(69 \%)$ of respondents have water available from their various sources throughout a given calendar year, while the rest have water available for periods less than a year (Fig. 4). This means that $31 \%$ of the farmers interviewed are unable to do three cropping seasons in any given year with $4 \%$ of them managing just one crop season, due to water being available for less than 3 months. Only $51 \%$ of beneficiaries in Beitbridge had water available all year round compared to $74 \%$ in Gwanda.

Of those beneficiaries who had problems in accessing water, the major problem faced was that of travelling long distance $(38 \%)$ to fetch water for the gardens. The differences between the better off farmers (cattle owners) and poorer farmers (non-cattle owners) were not significant but the poorer farmers were faced with breakdown of community boreholes, which they were dependent on. This group of farmers also complained that when these boreholes broke down it took too long for them to be repaired thereby affecting their crop production. These poor farmers also faced the problem of being denied access to water for their drip kit gardens especially during the dry season when the community priority was to water livestock.

Despite the existence of stakeholder-based water management structures from catchment level to water point level (such as a community borehole), conflicts related to the adoption of drip kits developed. Conflicts occurred

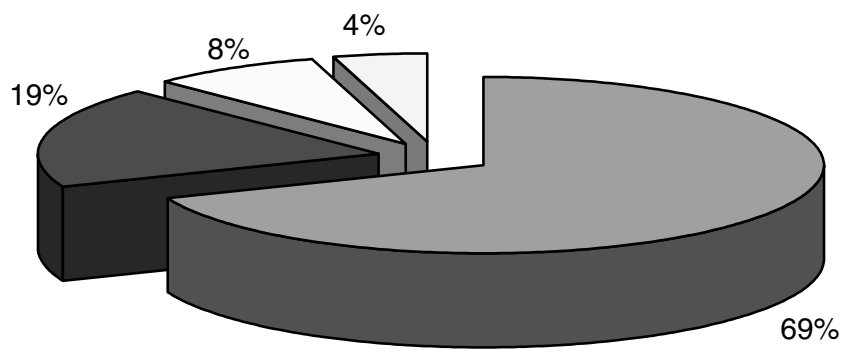

$\square$ All year round $\square 1 / 2-1 \mathrm{yr} \square 1 / 4-1 / 2 \mathrm{yr}$ Less than $1 / 4 \mathrm{yr}$

Fig. 4. Reported water availability among beneficiaries (Moyo, 2005). 
in areas where the drip kit users were dependent on community water points. These conflicts culminated in some cases with the drip kit users being barred from drawing water from the water sources. Their situation was not helped by the fact that beneficiaries did not have any representation in the water point committee to articulate their interests. Conflicts occurred during dry periods when most water sources would have dried up. Conflicts also occurred as a result of breakdown of water points such boreholes when the drip kit users were accused of causing demise of those water sources.

\subsection{Survey results: use of kit}

From the interviews with NGOs representatives and discussions with beneficiaries the recipients were encouraged to aim for three cropping cycles per year. It was claimed that all beneficiaries installed the kit and used it at least once. The kit used was the IDE kit (Frausto, 2000; Polak et al., 1997).

The beneficiaries interviewed had irrigated an area of around $100 \mathrm{~m}^{2}$. Only 2 of the 114 beneficiaries interviewed had used the kit to produce the expected 5 crop harvests over 2 years since distribution, owing to problems related to water shortage and also pests and diseases. About 51\% of the respondents had produced at least 3 harvests and $86 \%$ produced at least 2 harvests. Beneficiaries in Beitbridge used the kit less number of times compared to those in Gwanda. This could be attributed to the fact that almost half $(49 \%)$ of their water sources dried up during the dry season compared to only $25 \%$ in Gwanda. Only $5 \%$ of the beneficiaries in Beitbridge used the kit for more than 3 times compared to $30 \%$ of the beneficiaries in Gwanda.

Most of the cropping ( $61 \%$ ) by the beneficiaries was done during the wet season. This means that the kit was used primarily for supplementary irrigation during the wet season and on fewer occasions during the dry season owing to the water shortages. At any given cropping season beneficiaries could grow up to a maximum of 3 crops. In all the seasons the farmers grew maize in an attempt to improve their food security. They also grew high value crops, which included tomatoes, leafy vegetables, carrots and butternut, for sale.

Based on their experience, a majority of beneficiaries $(76.8 \%)$ agreed to the statement that the drip kit applied enough water as shown in Table 2.

This could be qualified by the previous study (Maisiri et al., 2005) that found that up to $50 \%$ of water saving was made when compared to surface irrigation. Likewise the majority of respondents agreed to the statement that the use of kit was labor saving $(68.3 \%)$ and is not time consuming $(65.3 \%)$. However, a large minority of poor farmers disagreed with the suggesting that drip kits are labor saving. This disagreement could be as a result of the long distances that were travelled by some of the poorer farmers to fetch water for their drip kits, thus requiring them to spend more time and labor than the better-off farmers. This could
Table 2

Perceptions of beneficiaries towards drip technology

\begin{tabular}{llll}
\hline Statement & $\%$ & $\%$ & $\%$ \\
& Agreeing & Neutral & Disagreeing \\
\hline Applies enough water & 78.6 & 3.4 & 18.0 \\
Use of drip kit is labor saving & 68.3 & 2.2 & 29.5 \\
$\begin{array}{lll}\text { Use of drip kit is time } \\
\quad \text { consuming }\end{array}$ & 29.4 & 5.3 & 65.3 \\
\hline
\end{tabular}

be related to the earlier observation on why less well to do farmers used the kit less than the poor farmers.

\subsection{Survey results: post-distribution services}

A third $(33 \%)$ of the beneficiaries were not aware of the parts of the kit that needed to be frequently replacement. This could be as result of the fact that most of them had used the kit for only a few seasons, and so fewer breakdowns would be expected. Of those who were aware, the majority $(29 \%)$ felt that the nozzle tubes needed to be frequently replaced as they broke or got blocked. This applied to those who were using the IDE kit. Eighteen percentage felt the pipes needed to be frequently replaced as they either broke or were attacked by the rodents while $12 \%$ felt they needed to have an extra filter. Despite apparent need for back up spares, almost all the beneficiaries $(96 \%)$ did not know where to get them if their kit broke down.

All the farmers received at least one training session on the use of the drip kits, mostly done by the implementing agencies $(74 \%)$ and the appointed contact farmers $(18 \%)$ with the rest carried out by government extension officers. The farmers were trained on installation of the kit; operation and maintenance of the kit and crop production techniques and few were trained on the fertilisation of their fields. There was no training on the marketing of produce. The assessment on level of training of beneficiaries focused on the operation and maintenance of the drip kit. The beneficiaries were tested on both the theory and practical of operation and maintenance of their drip kits. Although $80 \%$ of the beneficiaries were able to practically demonstrate how to carry out operation and maintenance tasks for their respective kits (in their gardens), this was not reflected by their theoretical knowledge. Just over half of the beneficiaries were knowledgeable on how they operated and maintained the kit. However, $35 \%$ were not able to give correctly the frequency of when the tasks (cleaning of nozzles, filters, and tank, and flushing of pipes) were supposed to be carried out.

Of those beneficiaries needing further training $44 \%$ felt they needed to be better equipped on the crop production techniques for various crops especially the high value crops. As could be expected, as result of lack of training on the marketing of crops, $38 \%$ of those needed training on how could market their produce. The differences between the two groups of farmers were significant with more poor farmers requiring marketing skills, as they needed to economically empower themselves. 


\section{Conclusions and recommendations}

The results show that although the drip kit distribution programme in the study area has achieved some of its objectives, it is under-performing due to a number of factors, most importantly availability and access to water. During the implementation of these drip kit programs not all these requirements were met, since the target group of farmers (the poorest) did not always fulfill all requirements, such as reliable access to a water source. They often are sharing those water resources that they do have access to, not only with other irrigators, but also with other uses, such as livestock watering and domestic use, both of which generally have a higher priority.

This problem reflects the manner in which the programme was carried out by many of the implementing agencies, who saw drip kit distribution as a relief effort and not as a development programme. Because of this, there was often poor monitoring and lack of back up, such as spares. It is therefore not suitable to offer drip kits as relief - especially to the poorest of the community - without also improving their access to water and reducing the

Box 1. Protocol for drip irrigation kits distribution programs

For the programme to sustainable, it is important that the NGOs to take aboard relevant government organs right from the inception of the program to the end so that by the time the NGOs conclude their work the programme can be handed over to such government institutions

1. Distance of water source

Objective: Ensure that the drip kit garden is close to the water source

Drip kit garden should be within $50 \mathrm{~m}$ of the water source or

Provide wheelbarrow or simple water cart to assist with transport of water for distances up to $250 \mathrm{~m}$

2. Reliability of water source

Objective: Ensure that the beneficiaries have a reliable water source

Before a kit is given the NGOs in collaboration with relevant Government Departments should make an effort to determine the reliability of the potential water sources

The potential water sources should be able to supply water for the kit all year round

3. Follow up visits

Objective: Ensure that the beneficiaries get prompt technical advisory service on the use of kit

During the year of inception the NGO should make high frequency follow-up visits to beneficiaries i.e. at least once every two weeks for the first crop, and then monthly

During the second year follow-up visits should be made once every cropping season, and then once every year thereafter

\section{Training}

Objective: Adequate training of beneficiaries

The NGO in collaboration with Government Extension Services should undertake the training

Training should be done in the following areas: Installation, repair and maintenance of drip kit

NB. Maintenance of the kit training should take cognisance of quality of water available for the drip kit in different areas

Cropping techniques including the cropping calendar

Irrigation scheduling

Pest control using cheaper traditional methods

As a way of motivating the beneficiaries field days and exchange visits by beneficiaries especially during the inception year

\section{Targeting}

Objective: Beneficiaries are people who are able to work in their respective gardens

NGO should ensure that the beneficiaries are able bodied persons who can work in their gardens

Provide water containers relevant to size and age of beneficiary-it is hard to lift a 201 bucket

\section{Spares}

Objective: Beneficiaries are able to carry out repair works in time on their kit without compromising their crop production

NGO should identify a local trade storeowner willing to stock the necessary spares, so that the beneficiaries can purchase them when they need them 
distance that they have to travel to obtain water. The NGOs should take this into account when selecting target farmers, and in developing co-ordinated relief and development programmes that address water availability as well as distributing technologies. As a prior step to distribution, an analysis of the existing water resources is needed, in order to assess availability and potential conflicts. The following protocol for NGO's has been developed (Box 1), which should be a better base for the development of sustainable drip kit programs.

\section{Acknowledgements}

This paper contains research results from a M.Sc. project by R. Moyo at the University of Zimbabwe, and is a contribution to WaterNet Challenge Program Project 17 "Integrated Water Resource Management for Improved Rural Livelihoods: Managing risk, mitigating drought and improving water productivity in the water scarce Limpopo Basin", funded through the Consultative Group on International Agricultural Research's Challenge Program on Water and Food. The research is also supported by a research grant from RELMA-in-ICRAF and a scholarship awarded to R. Moyo by the WREM Trust. The opinions and results presented in this papers are those of the authors and do not necessarily represent the donors or participating institutions. The co-operation of the Department of Agricultural Research and Extension Services in the Ministry of Agriculture and Rural Development (Matabeleland South Province), USAID LEAD and World Vision Zimbabwe has been essential and is gratefully acknowledged. David Rohrbach is thanked for advice in developing the questionnaire and protocol and Joe Rusike for a number of useful discussions.

\section{References}

Anderson, I.P., Brinn, P.J., Moyo, M., Nyamwanza, B., 1993. Physical resource inventory of communal lands of Zimbabwe. Natural Resources Institute Bulletin 60. London.

Ashton, P.J., Love, D., Mahachi, H., Dirks, P., 2001. An overview of the impact of mining and mineral processing operations on water resources and water quality in the Zambezi, Limpopo and Olifants Catchments in Southern Africa. CSIR Report to the Minerals, Mining and Sustainable Development Project, Southern Africa.

Behr, C., Naik, G., 1999. Applying micro-irrigation in the himalaya: a case study on the IDE's experience. Unpublished Report, IDE, USA.

Chigerwe, J., Manjengwa, N., van der Zaag, P., Zhakata, W., Rockström, J., 2004. Low head drip irrigation kits and treadle pumps for smallholder farmers in Zimbabwe: a technical evaluation based on laboratory tests. Physics and Chemistry of the Earth 29, 10491059.

FAO (Food and Agricultural Organisation), 2004. The State of Food Insecurity in the World: Monitoring Progress Towards the World Food Summit and Millennium Development Goals. Food and Agricultural Organisation of the United Nations, Rome.
Frausto, K., 2000. Developing irrigation options for small farmers. Report for Thematic Review IV. 2: Assessment of Irrigation Options. IDE, USA.

Government of Zimbabwe, 2003. National Population Census. Central Statistics Office, Harare.

Hussain, I., Giordano, M., Hanja, M.A., 2002. Water and Poverty Linkages: Case Studies of Large and Small Systems. IDE, USA.

IDE (International Development Enterprises), 2003. Low Cost Microirrigation Technologies for the Poor: Final Report. IDE, USA.

Keller, J., 2004. Irrigation technologies for small holders. Part 2 of paper under review for special edition of Irrigation Science.

Love, F., Madamombe, E., Marshall, B., Kaseke, E., 2005. Environmental flow requirements of the Rusape River, transboundary Save Basin, Zimbabwe. In: 6th WaterNet-WARFSA Symposium, Ezulwini, Swaziland, November 2005.

Maisiri, N., Rockström, J., Senzanje, A., Twomlow, S., 2005. An on-farm evaluation of the effects of low cost drip irrigation on water and crop productivity, compared to conventional surface irrigation system. Physics and Chemistry of the Earth 30, 783-791.

Moyo, R., 2005. Impact and sustainability of low cost drip kits, in the semi-arid lower Mzingwane Catchment, Limpopo Basin, Zimbabwe. M.Sc. thesis, Water Resources Engineering and Management Programme, University of Zimbabwe, Harare, unpublished.

Mutezo, M., 2005. Government to rehabilitate irrigation infrastructure. Interview of the Minister of Water Resources and Infrastructure Development by News Hour, Zimbabwe Broadcasting Holdings, Harare.

Nkala, E., 2003. A comparative analysis of agricultural and water productivity of the low cost micro-tube drip irrigation system and the conventional border strip irrigation system in the smallholder irrigation sub-sector in Zimbabwe. M.Sc. thesis, Water Resources Engineering and Management Programme, University of Zimbabwe, Harare, unpublished.

Polak, P., Nanes, B., Adhikari, A., 1997. The IDE low cost drip irrigation system. Journal of Applied Irrigation Science 32, 105-112.

Samakande, I., Senzanje, A., Manzungu, E., 2004. Sustainable water management in smallholder irrigation schemes: Understanding the impact of field water management on maize productivity on two irrigation schemes in Zimbabwe. Physics and Chemistry of the Earth 29, 1075-1081.

Senzanje, A., 1997. Developing and testing drip irrigation systems technologies for smallholder farmers. Paper presented at the "Joint International Conference on Agricultural Engineering and Technology Exhibition '97' held in Dhaka, Bangladesh, December 1518, 1997.

Senzanje, A., 1998. Evaluating the technical performance of low cost drip system for smallholder farmers. Paper presented at the International Conference of the Ghanaian Society of Agricultural Engineering on "Engineering Challenges in Developing Countries in the 21st Century", 20-25 September 1998.

Senzanje, A., Samakande, I., Chidenga, E., Mugutso, D., 2003. Field irrigation practices and the performance of smallholder irrigation in Zimbabwe: case studies from Chakowa and Mpudzi irrigation schemes. Journal of Agricultural Technology 5, 76-89.

Senzanje, A., Motsi, K., Rwakatiwana, P., 2004. Assessment of the technical performance and operational limits of a low cost drip irrigation system for peri-urban and smallholder farmers. Discovery and Innovations $16(1 / 2)$.

USAID Zimbabwe Report, 2004. Humanitarian Assistance Program Report for Zimbabwe, USAID, Harare.

Westarp, S., Chieg, S., Schreier, H., 2004. A comparison between low-cost drip irrigation, conventional drip irrigation, and hand watering in Nepal. Agricultural Water Management 64, 143-160. 